\title{
Electrospun nanofiber-based respiratory face masks-a review
}

\author{
Veereshgouda S. Naragund ${ }^{1,2}$ P. K. Panda ${ }^{1,2}$
}

Received: 8 November 2021 / Accepted: 19 January 2022 / Published online: 25 January 2022

(c) Qatar University and Springer Nature Switzerland AG 2022

\begin{abstract}
The severe acute respiratory syndrome coronavirus (SARS-CoV-2) pandemic of 2019 forced widespread use of face coverings as a mandatory step towards reducing infection by the virus. The face mask acts as a barrier for transmission of infected aerosols among its user and surrounding people. This has propelled pace of research and development of face masks around the world. This short review is an effort to present advances in materials and designs used for face masks. Details available in scientific literature and company brochures have been accessed and the use of nanomaterials and designs for the new generation of face masks have been discussed. Special attention was given to the face masks based on electrospun nanofiber-based membrane materials due to their nano-sized pores, light weight, and high filtration efficiency; therefore, they are commercially viable and popular among various products available in the market. Incorporation of metal organic framework (MOFs) and graphene have opened avenues to more advanced/multi-functional, reusable, and high capacity adsorption filtration membranes. Rapid prototyping/3-dimensional (3-D) printing techniques have been applied to shorten the time of manufacture of face masks. This review is expected to be very helpful for engineers, scientists, and entrepreneurs working on development of novel face masks required in plenty during this pandemic period.
\end{abstract}

Keywords Face mask $\cdot$ Filtration efficiency $\cdot$ Antimicrobial filters $\cdot 3-D$ printing $\cdot$ Nanofiber non-wovens $\cdot$ Electrospinning

\section{Introduction}

\subsection{Role of face mask in prevention of SARS-CoV-2 disease}

The use of face masks is mandatory in the fight against the SARS-CoV-2 pandemic prevailing in the world. In the absence of effective medicines to cure COVID-19, and vaccines that are recently introduced not being foolproof, the best approach is to keep away from this disease. In this direction, wearing suitable face masks is obligatory in order to restrict the entry of the virus into the body $[1,2]$. The virus is generally transmitted via aerosol droplets emanating from an already virus-affected person [3,4]. Therefore, the World Health Organization (WHO) recommends social distancing

$\checkmark$ P. K. Panda

pkpanda@nal.res.in

1 Materials Science Division, CSIR - National Aerospace Laboratories, HAL Old Airport Road, Kodihalli, Bengaluru 560017, India

2 Academy of Scientific and Innovative Research (AcSIR), Ghaziabad 201002, India norms, use of alcohol-based hand sanitizers for disinfection, and use of face masks in indoor as well as outdoor settings to reduce the spread of the disease during the pandemic [5]. This made procurement of face masks of required quality (N95) in the beginning months of COVID-19 a difficult task and the production of face masks was ramped up around the world. A recent study conducted [6] using two mannequins revealed that N95 masks were able to reduce the viral uptake by about $80-90 \%$. The face masks not only arrest the entry of the virus into the body of the user, but also found to reduce the distance travelled by cough cloud of the user [7] containing disease spreading aerosol droplets, thereby, minimizes the transmission to others.

\subsection{Objectives, methodology, and overview of the review}

Many research groups across the world have taken up the work on improvement of face mask particularly in design and development, selection, and use of appropriate material with intent to produce masks with multi-functionality, reusability, light weight, and comfort in usage along with large-scale manufacturing and cost reduction etc. At this

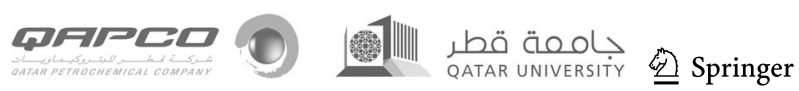


juncture, it was felt that there is a need of a review article summarizing the information available in the published literature for the benefit of researchers. Therefore, an effort was made in this direction with the following objectives: (i) to review different types of masks, their testing methods, structure, and functions; (ii) to identify and summarize the current research trends in the development of face masks with emphasis on latest materials and design with a special attention on nanofiber masks which are being commercialized; and (iii) to suggest future avenues for the face mask developments.

Towards the above objectives, this review presents the topics of interests as outlined in Fig. 1. To begin with, the review discusses some general aspects of face masks in Sect. 2. Then, the electrospinning process and its growing importance in face mask production is discussed in Sect. 3. The performance parameters and associated testing standards are discussed in Sect. 4. In Sect. 5, latest research trends were identified by analysing the scientific literature in two aspects: (i) the introduction of novel material for face mask and (ii) novel design changes of the face mask. It was found that novel organic and inorganic materials (biodegradable/antiviral nature, graphene, MoFs) were introduced along with nanofibers prepared by electrospinning process. Also it was observed from literature novel designs introduced by using latest manufacturing and

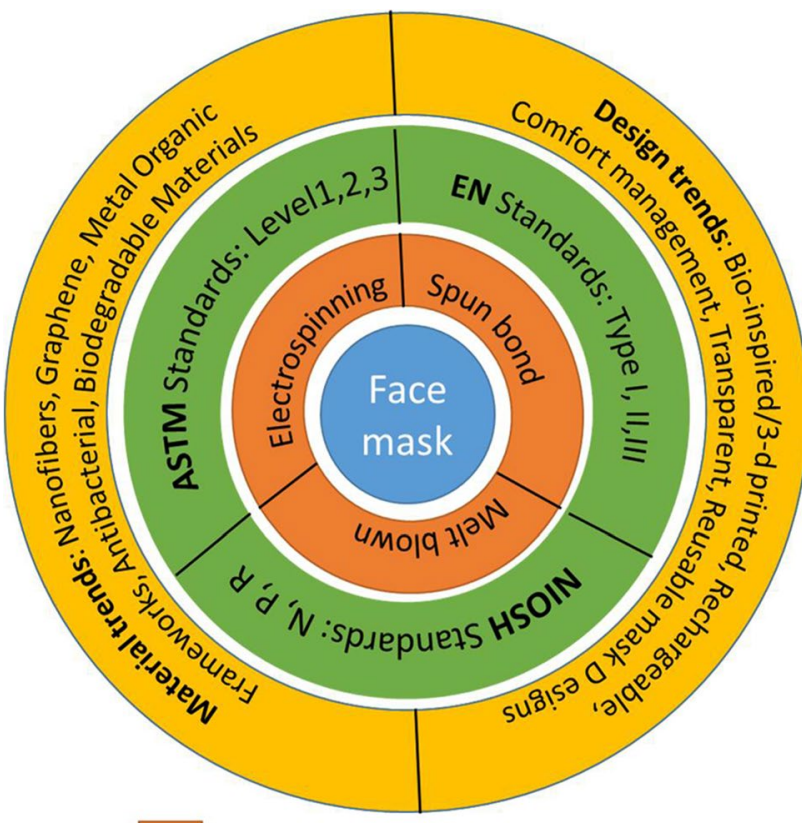

Methods of non woven material production

Major testing standards of face mask

Research trends in face mask

Fig. 1 Major topics covered in this review
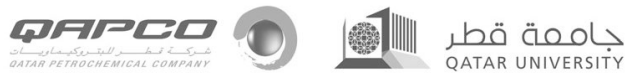

simulation technology such as 3-D printing which could optimize design for various requirements such as material cost, manufacturing time, weight, and wearer comfort for the new generation of face masks. Future prospects on face mask research are given in Sect. 6. The review ends with concluding remarks presented in Sect. 7.

\section{General aspects of face mask}

This section gives a general introduction on various aspects of face masks such as types, structure, and function of the face mask.

\subsection{Types of masks}

There are various types of face coverings available for protection from dust, bacteria/virus, cough droplets/aerosols, toxic gases, etc. Face masks such as dust masks and medical masks used during pandemics are discussed below.

\subsubsection{Dust or anti-pollution masks}

The dust or anti-pollution masks are made by stitching cotton/chiffon/silk/flannel/polyester/polypropylene woven or non-woven cloth materials in a form to fit and cover the nose and mouth loosely. They come in wide filtration efficiencies [8,9]. Masks with lower efficiencies are generally cheaper masks and widely available in markets. Nonstandard masks for general public use come in variety of shapes and sizes for example worn as bandana (triangular or square piece of cloth warped and tied around neck), home-made cloth masks which are prepared at home by t-shirt/vest fabric, store-bought mask (made of two- or three-ply non-woven fabric), and balaclavas and neck gaiters (tube-like cloth that can be slipped/removed over from head to neck). They are able to filter out particles of size larger than $2.5 \mu \mathrm{m}$ for example, dust particles, mites, dander, and pollen effectively, but not smaller $(\sim 50 \mathrm{~nm})$ aerosol particles [10]. Some masks may have aluminium/ plastic clips on the nose portion of the mask to give some degree of fitting to the wearer's nose. They are used by the general public as well as professionals except healthcare workers (HCWs) and find applications in, but not limited to, (i) outdoor settings by pedestrians on footpaths/motorists riding a bike on the road to block vehicle-generated dust; (ii) indoor household cleaning works; (iii) at woodworking, granite, and other such industry. They are not suitable to be worn by medical professionals inside hospital settings for example, in operation theatre. 


\subsubsection{Medical masks}

The protection of HCWs from transmittable disease is utmost important to avoid collapse of healthcare system. Therefore, medical masks are specially designed for medical professionals and worn by HCWs and patients in medical settings such as operation theatres or out-patient examination rooms [11]. The medical masks are made of highgrade filtering materials capable of reduction of sneeze/ cough droplets, protect from blood splash from patient to the doctors during operation/surgery, and related infectious diseases.

\subsection{Function of a face mask}

The broad function of a face mask is to protect the wearer from the environmental hazards present in air. Surrounding air is polluted with gaseous vehicular exhaust (oxides of sulphur, nitrogen, and carbon), as well as with volatile organic contaminants (VOCs) which may be released due to many natural causes such as decomposition of organic matter or anthropogenic (industrial) activities. Indoor activities such as smoking or burning of candles/incense sticks would also release many VOCs. The high concentrations exposure of VOCs may cause interactions within the human body causing asthma, anaemia, or effecting the nervous system. Thus, a requirement of a face mask is to reduce the VOCs. Meanwhile, the VOCs may also interact with earth's protective ozone layer causing its depletion.

In addition, air quality is also reduced with suspended particulate matter (PM) generated due to various anthropogenic activities. PM is classified into 3 categories based on the size and risk levels: (i) PM10 i.e. dust particulates of size $10 \mu \mathrm{m}$ or smaller, these reduce visibility and air quality at construction sites, and due to vehicular movement on an unpaved road; (ii) PM2.5 i.e. particles having sizes more than $2.5 \mu \mathrm{m}$ which can deposit on the upper respiratory region such as the nose and throat; (iii) PM0.3 i.e. particles having size between 2.5 and $0.3 \mu \mathrm{m}$ which can penetrate deep inside the lung into the parts which is known as alveoli and affect human health. Therefore, another function of a face mask is to filter out the particulate contaminants.

A face mask is a protective device that in general may or may not meet fluid barrier. Medical face masks worn by the healthcare workers (HCWs) should protect the wearer from any blood splashes occurring during the surgery. Thus, these medical face masks should provide resistance to blood splash. During the pandemic situations, the air could be suspended with biological contaminants that could be carried into the atmosphere either as droplets of cough emitted by an infected person or as aerosol of virus/ bacteria formed as a result of drying of the smaller droplets by a dry (low humidity) and warm atmosphere. These pathogens and droplets can cover wide range of sizes between $50 \mathrm{~nm}$ and $500 \mu \mathrm{m}$. Therefore, the masks should repel droplets and blood and filter out fine biological contaminants and preferably be anti-bacterial in nature.

Therefore, face masks are expected to (i) protect the wearer from contaminants such as particulates such as dust, bacteria, and sneeze droplets present in the surroundings while being permeable to air and provide blood splash resistance (for HCWs) to the wearer and (ii) prevent/reduce expulsions of cough and sneeze by the wearer into the surroundings so as to keep the surrounding harm-free from infection especially during the pandemic situations. Some masks come with exhalation valves/ventilation fans [12] which reduce exhalation pressure drop and also reduce $\mathrm{CO}_{2}$ accumulation. However, during the pandemic outbreak (such as COVID-19), masks with exhalation valves may leak the virus (such as SARSCoV-2). So, masks having an exhalation valve are not recommended during a respiratory disease outbreak. Face masks can also be used by the general public as well as HCWs for source control (i.e. avert transmission from an infected individual who may or may not have symptoms of COVID-19) in accordance with Centers for Disease Control and Prevention (CDCs) recommendations [5]. Thus, face masks are made up of several layers of non-woven/ woven fabric materials that are carefully selected (so as to provide the above said functional properties as needed by a customer) and stitched together to make a barrier between the environment and wearer's mouth/face.

\subsection{Structure of a face mask}

A mask is made up of at least three or more layered composite structure consisting of two polyester/polypropylene non-woven and a fine fiber filtration membrane within. Additionally, another middle layer of activated carbon fabric may be added for the adsorption of VOC [13]. In most cases, a mask is also expected to be non-collapsible; therefore, a modacrylic layer is included to provide a tight fit around the wearer's nose and mouth. Thus, most commercial masks are made from four- to five-layered fabric materials [12]. The layer contacting the skin should be soft non-woven fabric, providing comfort to the wearer, and hydrophilic in nature which holds cough droplets. The outer most membrane may be a liquid/blood repelling membrane. The middle layer membrane is a performance filter membrane having small pore size with high filtration efficiency [2]. The material for the middle layer can be produced by process such as melt blowing or electrospinning [14-16]. The next section discusses electrospinning process, its advantages over melt blown fibers, and its recent industrial adoption in face masks.

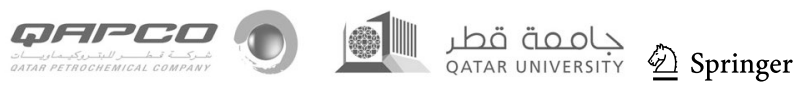




\section{Electrospinning process and nanofibers for face masks}

The electrospinning process is currently the most researched process to manufacture the performance layer of nanofiber face mask non-woven, apart from traditional processes such melt blowing processes.

\subsection{The electrospinning process}

Electrospinning is a process to form nanofiber materials with the aid of a high electrical voltage applied to polymer solution/melt [17-19]. Anton Formhals obtained first of many patents in the 1930s disclosing apparatus and process for spinning of man-made fibers from cellulose acetate solutions by use of electrical voltage [17]. Later in the 1990s, research interest gained momentum $[18,19]$ and subsequently electrospinning seen faster industrial adoption of electrospinning during last decade with rapid progress in technology [20]. The fibers by electrospinning process are obtained in variety of forms, for example, as yarn [21], membranes [22, 23], and even as 3-D scaffolds [24].

The electrospinning process involves two steps: (i) preparation of the polymer/dope solution; (ii) electrospinning of solution into fibers $[19,25]$. The polymer to be electrospun is dissolved in appropriate solvent to obtain solution. Therefore, the electrospinning process can be physically interpreted as a process that essentially transforms the polymer beads/powder into polymer fiber products. The physical transformation happening during the electrospinning is shown in Fig. 2. An intermediate phase i.e. a solution or melt phase is used to aid the transformation between powder or bead form of polymer to fiber form. Therefore, electrospinning process can be physicallyinterpreted as a process that essentially transforms the polymer bead particles/ powder intopolymer fiber products.

A schematic of a lab-scale electrospinning setup is shown in Fig. 3. Generally, a syringe pump with a metallic capillary needle is used for continuous supply of polymer solution. The high voltage is applied between the capillary and a metallic collector. A drum collector warped with aluminium foil is connected to neutral/opposite polarity acts as a counter electrode for collection of fibers. To prepare ceramic

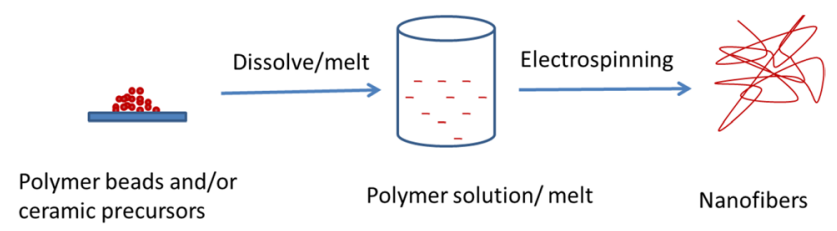

Fig. 2 The physical interpretation of the electrospinning process

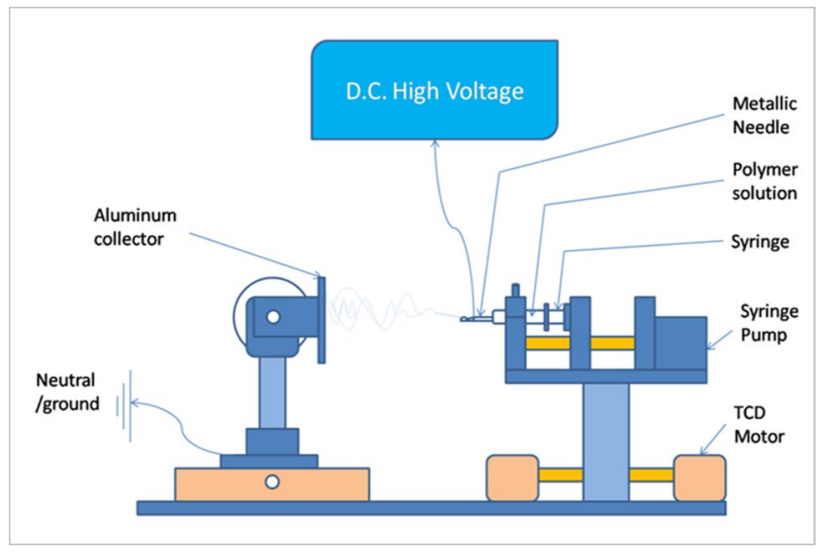

Fig. 3 Schematic of a lab-scale electrospinning equipment [28]

fibers, ceramic precursors (in the range of 30 to 50\%) are doped into polymer solution $[26,27]$. When applied voltage crosses a limiting value, a thin jet is ejected from the solution droplet. The jet while travelling towards the collector subdivides into micro to nanofibers due to its own electrostatic repulsive forces of charged polymers. The solvent evaporates quickly from high surface area available over the submicron fibers. With the passaging time, a thick membrane or even 3-D structures containing of nanofibers will develop on the collector [24].

Nanofiber membranes prepared by electrospinning method have several advantages such as (i) scalability [20]; (ii) high porosity along with small pore size can providing higher water/air flow rates [29]; (ii) high surface area providing ample space for functionalization of membranes to efficiently remove multiple pollutants such as particles and bacteria/virus as well as harmful gas [30]; and (iii) fibers with diameters $\sim 100 \mathrm{~nm}$ can provide low filter resistance for air filtration due to slip flow phenomena [31].

\subsection{Electrospinning process parameters}

Electrospun nanofiber morphology and fiber diameters are affected by process variables. These are classified into two groups:

1. Environmental variables: These are the parameters of the environment such as temperature and humidity inside the cabinet/room where the electrospinning apparatus is kept. These are important because polymers in the nanofiber form having high surface area and can interact with the humidity absorbing water molecules if the polymers are hydrophilic and water dissolving polymers may fuse/weld at the fiber overlapping points when humidity is very high [32]. For hydrophobic polymers/water insoluble, there was not much effect of humidity. Combination of solvents having low or high boiling points evaporate 
at different rates under different humidity, when having low or high boiling points, thus altering fiber morphology from cylindrical to wrinkled fibers or even creating secondary structures on the surface of the fibers such as dimples/pores [33]. Some fibers showed changes in mechanical properties such as increased tensile strength at low relative humidity [34]. Therefore, it is needed to gain control over these variables in order to achieve uniform fiber properties in electrospun polymers.

2. Processing parameters: These parameters are related to the material and device control while carrying out the electrospinning other than environmental parameters. The polymer molecular weight, and concentration of polymer in solution [35], solvent parameter such as conductivity [36], surface tension [37], and boiling point [38] are some of the material-driven parameters that affect the fiber morphology. Electrical voltage applied to the spinning solution/needle tip, the needle tip to collector distance (TCD), and the volume/mass flow rate of the solution are some of the device-controlled process parameters [39].

\subsection{Nanofibers for face masks}

\subsubsection{Advantages of nanofibers over microfibers}

The melt blown fibers are being fast replaced with electrospun nanofibers as face mask materials due to (i) small pore size enabled by small fiber diameters which provides high filtration efficiency for submicron particles, bacteria, viruses; (ii) electrospinning process can generate fibers with diameters in the range of $50-100 \mathrm{~nm}$ that provide minimum resistance to air due to slip flow occurring around the fibers having diameters comparable to the mean free path. smaller fiber diameters enables low pressure drop due to slip flow of air and also surface loading of dust supporting better reusability by reverse pulse; and (iii) high surface area enables higher dust capture for longer life, along with design flexibility such as low weight, soft feel, and surface functionalization to capture specific toxins/gases.

A comparison between melt blowing and electrospinning process [19, 28, 40-45] is presented in Table 1. Both processes create non-woven fabrics. Both processes have their own advantages and disadvantages. Apart from air filtration, electrospun nanofiber membranes are also increasingly used in water clarification technologies [25, 46, 47].

\subsubsection{Steps in manufacturing of nanofiber face mask}

The nanofiber membranes are highly porous in nature; therefore, they are weak in mechanical properties. A suitable support fabric (polypropylene (PP), polyethylene (PE), polyethylene terephthalate (PET)) is often used, and the electrospinning is performed on a support fabric wound over an aluminium backing plate/roller. Another polyester nonwoven is laid upon the nanofiber membrane, and heat setting operation/welding is carried out to obtain a dimensionally stable mask. This is schematically shown in Fig. 4 (a). The manufacturing process for the electrospun nanofiber face mask is outlined in Fig. 4 (b). The two main steps are:

(i) Electrospinning of appropriate nanofibers onto a support fabric. The amount of nanofiber depends on polymer chosen and filtration quality required. Generally, 0.5 to $5 \mathrm{~g} / \mathrm{m}^{2}$ have been used to achieve depending upon required levels of filtration efficiency and application type [48]. Polyesters/polypropylenes $\left(10-25 \mathrm{~g} / \mathrm{m}^{2}\right)$ which are available in free markets are chosen as support fabric because of their property of heat setting which gives dimensional stability, among other desirable properties.

(ii) Placement of top fabric and heat setting of the 3 layers to give dimensionality. For heat setting operation [49], the 3-layer composite is placed onto a mould that assumes the shell shape which covers the nose and chin of the wearer. Folding/origami technique

Table 1 Some similarities and differences between melt blowing and electrospinning

\begin{tabular}{|c|c|c|}
\hline Sl. no & Melt blowing & Electrospinning \\
\hline 1 & $\begin{array}{l}\text { Fibers are carried to collector by air stream at high velocity/pres- } \\
\text { sure [40] }\end{array}$ & Fibers are carried to collector by electrical high voltage force [19] \\
\hline 2 & Substrate can be made of any metallic/non-metallic material & $\begin{array}{l}\text { A metallic conductive collector is needed which could further be } \\
\text { warped with polymer non-woven substrates }\end{array}$ \\
\hline 3 & Polymer is heated and melt is processed & Polymer solutions, colloids, and melts can be processed \\
\hline 4 & $\begin{array}{l}\text { Charging of fibers occurs generally in post processing operation } \\
\text { [41] }\end{array}$ & $\begin{array}{l}\text { Charging is inherent due either material (charged polymers) or } \\
\text { processing (high voltage) nature of process }\end{array}$ \\
\hline 5 & $\begin{array}{l}\text { The non-woven fabric can be used almost without much modifica- } \\
\text { tion due to good mechanical properties }\end{array}$ & $\begin{array}{l}\text { The thin nanofiber membrane has limited strength, often requires } \\
\text { support non-woven [42] and heat treatment operations [43] }\end{array}$ \\
\hline 6 & $\begin{array}{l}\text { Fiber diameters are generally in the range of } 1 \text { to } 20 \mu \mathrm{m} \text { [44]; how- } \\
\text { ever, fibers with diameters }<1 \mu \mathrm{m} \text { can also be fabricated [45] }\end{array}$ & $\begin{array}{l}\text { Fiber diameters generally vary in the range of } 40-500 \mathrm{~nm}[28] \text {. } \\
\text { Higher fibers can be formed with higher viscosity solutions }\end{array}$ \\
\hline
\end{tabular}




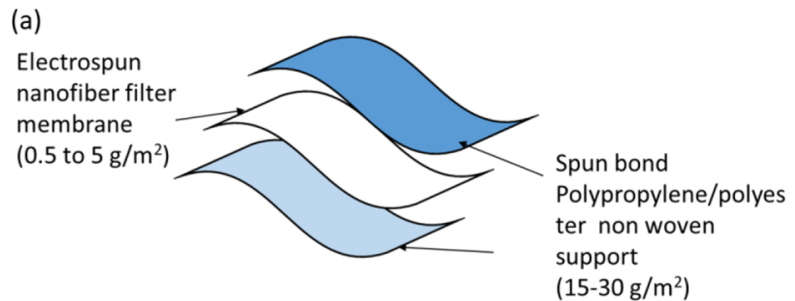

(b)

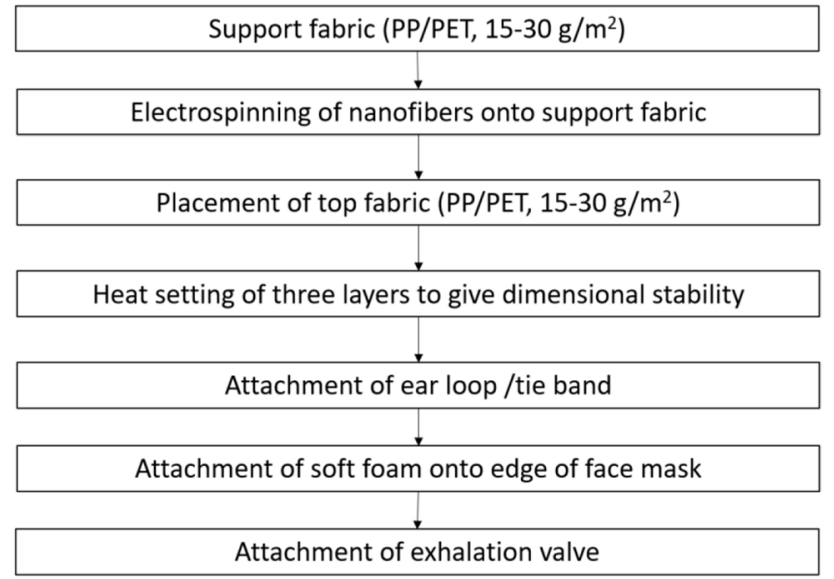

Fig. 4 a Schematic view of three-layered nanofiber mask's composite fabric; $\mathbf{b}$ process flow diagram of nanofiber face mask manufacturing

may also be used to give 3-dimensional shapes. The heat setting temperatures of some polymers such as polyethylene terephthalate, polyamide- 6 , and polyamide-66 are $210^{\circ} \mathrm{C}, 190{ }^{\circ} \mathrm{C}$, and $225^{\circ} \mathrm{C}$ respectively [49].

\subsubsection{Commercial adoption of nanofibers as face mask fabric}

In recent years, electrospinning has been commercially adopted by many companies to manufacture nanofiber nonwovens for use as a high-performance filtration layer in face masks and has been introduced in their products. By scanning through their product catalogues, some commercial nanofiber face masks along with their performances have been summarized in Table 2. From bacterial and particulate filtration efficiency data, it can be seen that nanofiber masks have $>98 \%$ filtration efficiency, which exceeded the N95 filtration limits. From this, it is concluded commercially successful use of nanofiber-based technology in face mask application.

\section{Performance and testing standards for face mask}

This section gives a brief description on performance parameters and major testing standards for the certification of face masks.

\subsection{Performance parameters for face masks}

The most important performance parameters for any face masks are bacterial/particle/viral filtration efficiency (BFE/ PFE/VFE). For testing and certifying medical as well as dust masks, model particles such as bacteria/virus, $\mathrm{NaCl}$, or polystyrene latex spheres in the form of aerosol are used in different testing methods. Properties of these particles [46] are summarized in Table 3. For the PFE, the test employs 0.1 or $0.3 \mu \mathrm{m}$ polystyrene latex spheres mixed into test air stream (aerosol) and passed through mask materials. Laser particle counters are used for detecting (counting) upstream and downstream aerosol particles. From these counts, the filtration efficiency is given as the ratio of difference of upstream and downstream particles to the upstream particle counts. For bacterial/viral filtration efficiency, aerosols containing pathogens are passed through membranes and culture plates (cascade impactor) containing microbial nutrient (agar) are used to count colonies of bacteria after incubation for a period of time. Medical face masks are tested for resistance for penetration of synthetic blood penetration. The test uses simulant blood consisting of a blend of a red dye, thickening agent, and many others; however, it is not a representation of all characteristics of blood such as polarity (wetting characteristics) and contents of blood cell [50]. Therefore, we note that an additional human blood contact angle test could provide more information regarding the wetting characteristics of the filter membrane.

Other parameters such as flame retardancy, differential pressure/breathability, and biocompatibility and microbial cleanliness are also tested depending upon requirements. Furthermore, respirator masks can also be subjected to a fit test, valve leakage test, exhalation and inhalation resistance tests, and end-of-life pressure drop test.

\subsection{Testing and classification of face masks}

Standard testing methods are followed based on the end application of the masks. Major institutions issuing testing standards are the American Society for Testing and Materials (ASTM, 2100-19), Food and Drug Administration (FDA), and National Institute of Occupational Safety and Hazard (NIOSH), and European standards (EN 14,683:2019) are adopted by standard third-party testing 


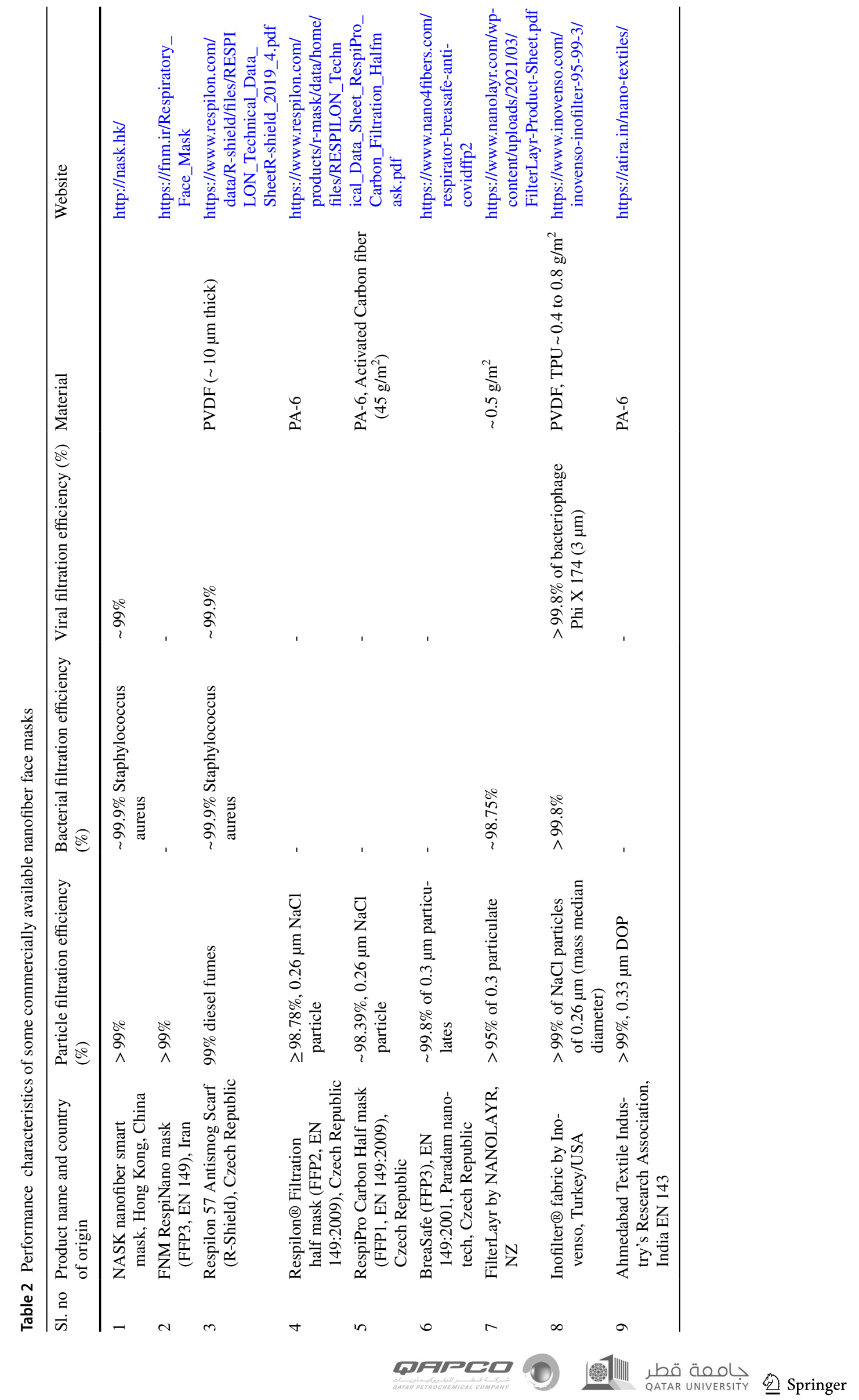


Table 3 Description of test agents used in various testing standards for filtration efficiency of face masks (adapted from [51])

\begin{tabular}{|c|c|c|c|c|}
\hline Test method & Source document & Aerosol type and condition & Particle size & Particle concentration \\
\hline NIOSH & 42 CFR Part 84 & $\mathrm{NaCl}$, neutralized particle & $.075 \mu \mathrm{m}$ CMD $(\mathrm{GSD}<1.86)$ & $<200 \mathrm{mg} / \mathrm{m}^{3}$ \\
\hline FDA-PFE & $\begin{array}{l}\text { 1) FDA Guidance Document } \\
\text { (SM } 501(\mathrm{~K})) \\
\text { 2) ASTM F2100 } \\
\text { 3) ASTM F2999 }\end{array}$ & $\begin{array}{l}\text { Polystyrene latex spheres, } \\
\text { Unneutralized (FDA Guid- } \\
\text { ance Document) }\end{array}$ & $\begin{array}{l}0.1 \mu \mathrm{m} \text { (FDA Guidance Docu- } \\
\text { ment) }\end{array}$ & $\begin{array}{l}\text { Generate } 10^{7}-10^{8} \text { particles } / \mathrm{m}^{3} \\
\text { and dilute as required (ASTM } \\
\text { F2299) }\end{array}$ \\
\hline ASTM-PFE & ASTM F2299 & Latex spheres, neutralized & $\begin{array}{l}0.1-5 \mu \mathrm{m} \text { (mono-disperse } \\
\text { aerosol; MPS) }\end{array}$ & $\begin{array}{l}\text { Generate } 10^{7}-10^{8} \text { particles } / \mathrm{m}^{3} \\
\text { and dilute as required }\end{array}$ \\
\hline FDA-BFE & $\begin{array}{l}\text { 1) FDA Guidance Document } \\
\text { (SM } 501(\mathrm{~K})) \\
\text { 2) ASTM F2100 } \\
\text { 3) ASTM F2101 }\end{array}$ & $\begin{array}{l}\text { Staphylococcus aureus, } \\
\text { (ASTM F2101) }\end{array}$ & $\begin{array}{l}3 \pm 0.3 \mu \mathrm{m} \text { (MPS) (ASTM } \\
\text { F2101) }\end{array}$ & $\begin{array}{l}2200- \pm 500 \text { viable particles per } \\
\text { test (ASTM F2101) }\end{array}$ \\
\hline ASTM-BFE & ASTM F2101 & $\begin{array}{l}\text { Staphylococcus aureus } \\
\text { bacteria }\end{array}$ & $3 \pm 0.3 \mu \mathrm{m}(\mathrm{MPS})$ & $\begin{array}{l}2200- \pm 500 \text { viable particles } \\
\text { per test }\end{array}$ \\
\hline VFE & No standard method available & PhiX174 virus & $\begin{array}{l}3 \pm 0.3 \mu \mathrm{m} \text { (MPS) (adapted } \\
\text { from ASTM F2101) }\end{array}$ & $\begin{array}{l}\text { 1700-2000 plaque-forming } \\
\text { units per test (adapted from } \\
\text { ASTM F2101) }\end{array}$ \\
\hline
\end{tabular}

Table 4 Suggested mask under various scenarios and their requirements

\begin{tabular}{|c|c|c|}
\hline Wearer (scenario) & Suggested mask & Suggested mask requirements \\
\hline Pedestrians (no pandemic, heavy traffic) & $\begin{array}{l}\text { Dust mask/cloth mask/FFP } 1,2 \text { with carbon fabric } \\
\text { (reusable) }\end{array}$ & $\begin{array}{l}\text { Reduce PM and VOCs (low reduction require- } \\
\text { ment); respiratory protection }\end{array}$ \\
\hline Industrial worker (industrial setting) & $\begin{array}{l}\text { N95 respirator/P95 particulate respirator mask } \\
\text { with carbon fabric }\end{array}$ & $\begin{array}{l}\text { Reduce } \mathrm{PM} \text {, aerosols, gaseous emissions/VoCs } \\
\text { (high reduction requirements); respiratory } \\
\text { protection }\end{array}$ \\
\hline General public (pandemic) & Fabric mask (3-ply mask) & $\begin{array}{l}\text { Reduce expulsion/inhalation of cough droplets or } \\
\text { aerosol when speaking/breathing, no valve }\end{array}$ \\
\hline $\begin{array}{l}\text { Infected persons, Primary contacts/care } \\
\text { givers of infected person }\end{array}$ & N95 respirator/medical mask & $\begin{array}{l}\text { Reduce PM, cough droplets, biological aerosol, no } \\
\text { valve, respiratory protection, and source control }\end{array}$ \\
\hline Healthcare workers & Medical face mask & $\begin{array}{l}\text { Filter biological aerosol, repel blood, cough drop- } \\
\text { lets, repel blood }\end{array}$ \\
\hline Doctor (operation theatre) & Surgical mask/medical N95 respirator mask & $\begin{array}{l}\text { Repel blood, filter cough droplets and aerosol } \\
\text { (high reduction requirements), no valve }\end{array}$ \\
\hline
\end{tabular}

laboratories for certifying medical face masks. For certifying dust/particle masks in industrial work places, ASTM F2299, EN149, and NIOSH are used. For certifying medical masks ASTM 2100, FDA standards are followed. Medical face masks without liquid/blood barrier protection are allowed for source control of SARS-CoV-2 spread by the patients under emergency use authorization in view of the COVID-19 pandemic.

A dust mask/particle filtering mask with $<80 \%$ particle filtration efficiency (PFE) is generally un-rated. Performance requirements for three classes of EN149 particlefiltering half masks are required to be $>80 \%$. The EN149 standard classifies masks into filtering face piece (FFP) $F F P 1, F F P 2$, and FFP3. The protection offered by masks increases with increasing number i.e. FFP1, FFP2, and FFP3 are $>80 \%,>94 \%$, and $>99 \%$ [52].

\subsubsection{The NIOSH performance standards for respirator face masks}

The NIOSH masks are designated as N, P, and R based on application environment and in combination with 95, 99, and 100 based on \% particle filtration efficiency. The N-masks are used for a non-oil atmosphere such as dry dusty atmospheres. The mask that passes a test is designated and marked by that name. An N95 mask is $>95 \%$ efficient in removing $0.1 \mathrm{~nm}$ particles in a non-oily atmosphere. R-masks are resistant to an oily atmosphere and restricted for a single use of a shift up to $8 \mathrm{~h}$ of continuous or intermittent use in an oily environment. Reuse is not permitted beyond 8 h. P-masks are oil-proof masks with possibility to reuse depending on the manufacturer's instructions. It is important to have appropriate knowledge on the use of face masks by 
different people during the pandemic and other situations. Therefore, Table 4 presents the face masks suggested for use in different scenarios along with their requirements.

\subsubsection{The ASTM and European standards for medical face masks}

The ASTM and European standards are the most widely used and recognized standards. The order of protection increases with the level. While the ASTM classifies the mask into level 1, level 2, and level 3, the European standards grade the masks as type I, type II, and type IIR [53]. These masks are further discussed in the sections below. A level 1 mask is for short medical procedures and examinations that do not involve heavy aerosols, spray, or fluids. Level 2 masks are used for moderate protection in settings of low to moderate levels of aerosols, spray, and/or fluids such as dental hygiene prophylaxis. Level 3 masks offer maximum barrier protection and used when heavy levels of bacterial aerosol and/or fluids are present in the atmosphere. The performance requirements such as BEF and PFE required are $>95 \%$ for level 1 masks and are $>98 \%$ for level 2 and level 3 masks. Blood penetration resistance required is $80 \mathrm{mmHg}, 120 \mathrm{mmHg}$, and $150 \mathrm{mmHg}$ for level 1, level 2 , and level 3 masks respectively [50,54].

The EN 14,683:2019 medical mask does not require a particle challenge. However, a microbial cleanliness test is required. While the BFE is $95 \%$ for type 1, it is $98 \%$ for type 2 and type 3 . The breathability/pressure drop is $40 \mathrm{~Pa} /$ $\mathrm{cm}^{2}$ for types 1 and 2 and $60 \mathrm{~Pa} / \mathrm{cm}^{2}$ for type 3 masks. Fluid resistance is required up to $16 \mathrm{kpa}$ only for type 3 masks [55].

\section{New trends in materials and designs for face mask}

\subsection{Design trends}

Recent research trends in design enhancement of face masks are summarized in Table 5. They are bio-inspired materials and designed of transparent filters by use of combination of electrospinning/3-D printing, use of triboelectric generators for charging, and inactivation of virus by incorporating thermal elements inside mask, reusable masks, etc. The section below reviews literature that incorporates one or more novel concepts.

\subsubsection{Bio-inspired/3-D-printed masks}

J. Yuk et al. (2020) proposed a 3-D-printed novel bioinspired filtration mask design based on olfactory chambers of animals with high olfactory capabilities (dog, pig, rodents, etc.) using CT scan images. It was observed that chambers have a complicated maze-like structure with gap width and the radius of curvature in the order of a millimetre or slightly less. The 3-D-printed filters with various tortuous air pathways were tested for inhalation/exhalation resistance and filtration performance. It was found new 3-D-printed filters work well to collect micron-sized particles [56]. H. Liu et al. (2020) optimized biomimetic spider-net-like 2-D nano-net structures with fiber diameter $\sim 30 \mathrm{~nm}$ using PAN polymer in $\mathrm{LiCl} / \mathrm{DMF}$ solvent. It was reported that $0.1 \mathrm{wt} \%$ $\mathrm{LiCl}$ in $4 \mathrm{wt} \%$ PAN/DMF solution yielded large amount of nano-net structures. The membrane of $0.4 \mu \mathrm{m}$ thick and areal weight of $0.68 \mathrm{~g} / \mathrm{m}^{2}$ gave high efficiency of $99.996 \%$ of $0.3 \mu \mathrm{m}$ PM [57]. P. Piombino et al. (2021) custom designed and 3-D printed six face masks of polyurethane and polylactic acid as materials for mask cover and filter slot respectively. Single N95 mask fabric cut and put into filter slot and tested for fit on 3 male and 3 female health workers thus maximizing the utilization of filter fabric. The average time to virtually design the mask by using software was $33 \mathrm{~min}$ and average time for printing of masks $10 \mathrm{~h}$. The final cost of manufacture was about $\$ 5$. The user trail among health workers revealed that the device provided very good fit and comfort [58].

\subsubsection{Rechargeable masks}

The rechargeable masks can restore the antimicrobial ability via mechanical pressure or light radiation sources. R. Zheng et al. (2020) investigated novel enhancement of filtration efficiency of disposable surgical masks by charging the polypropylene non-woven using triboelectric charge generation by rubbing ( 400 times) non-woven kept between an aluminium plate and PTFE film. It was found that the tribocharging process almost doubled the efficiency of $0.3 \mu \mathrm{m}$ PM. They also reported that $80{ }^{\circ} \mathrm{C}$ dry heating is a suitable method to disinfect and even after 10 times reuse the filter materials exhibited $>95 \%$ filtration efficiency [59]. Si. Y et al. explored various photobiocidal agents capable of releasing reactive oxygen species (ROS) such as hydroxyl radicals $(\bullet \mathrm{OH})$, superoxide $\left(\bullet \mathrm{O}^{2-}\right)$, and hydrogen peroxide $\left(\mathrm{H}_{2} \mathrm{O}_{2}\right)$, under dim light conditions and regenerate ROS under daylight conditions. Various benzophenones and polyphenols were grafted onto electrospun PVA-co-PE nanofibers. Combination of benzophenone tetracarboxylic dianhydride (BD) and chlorogenic acid (CA) exhibited highest ROS generation due to charge transfer feature of $\eta-\pi$ transition [60].

\subsubsection{Comfort management}

Medical staff tend to use the masks several hours long continuously; thus, comfort of the mask during the usage is an important driving force for the usage of face masks.

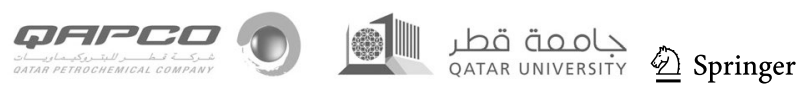




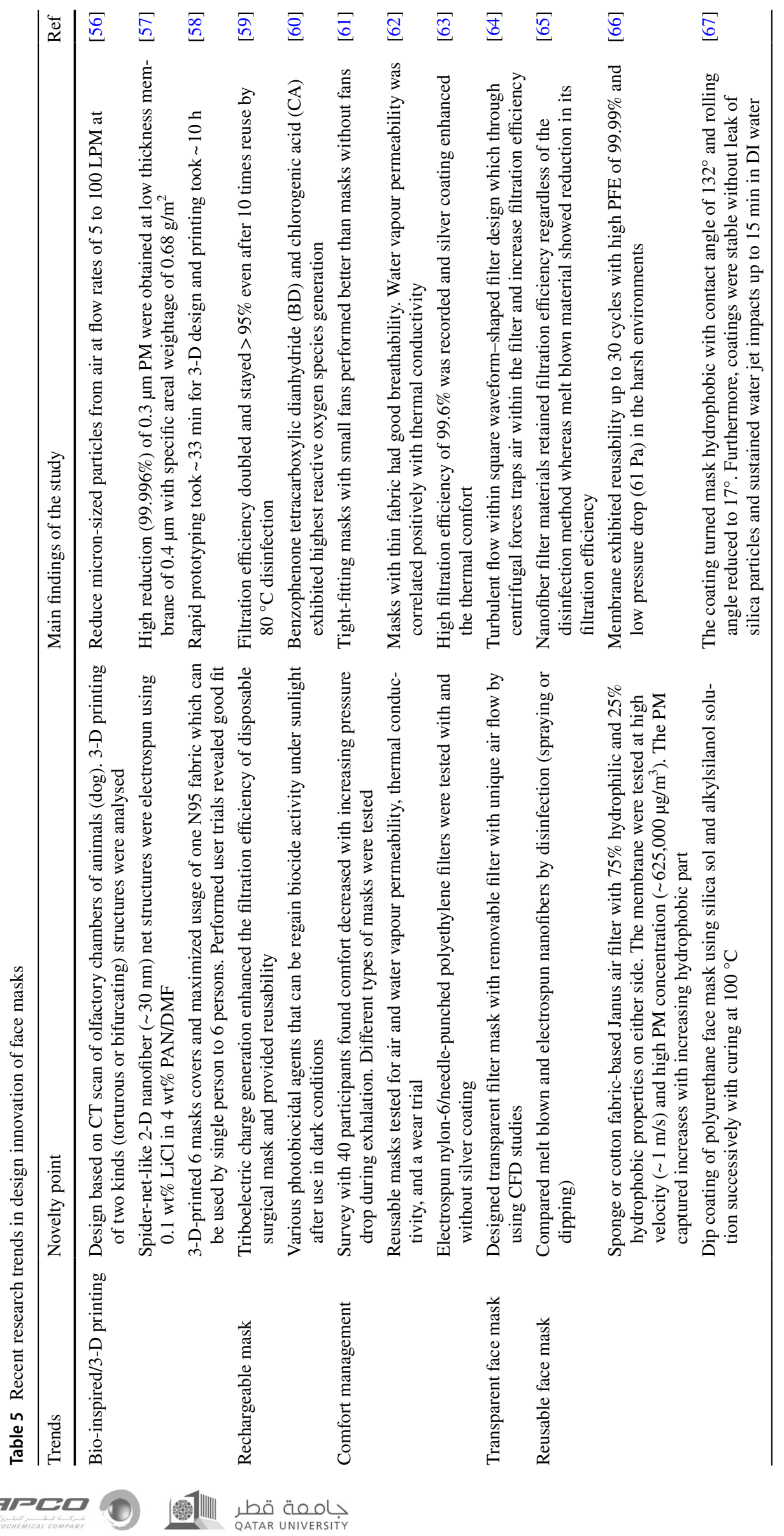


The mask should have low energy cost of breathing, in other words, pressure drop across the filter fabric should be as low as possible without compromising on filtration efficiency. S. Choi et al. (2020) studied comfort of several face masks by a survey of 40 participants and correlated the comfort negatively to pressure loss (measured by experimental manikin setup) during inhalation. It was also found that, while the masks without a fan were not as comfortable, tightly fitting masks along with small add-on fans proved comfort due to positive pressure, while maintaining high filtration efficiency [61]. The mask should be permeable to moisture so that the micro environment inside the face mask is comfortable during the application and not irritating to the wearer. Lee et al. (2020) tested various commercially available reusable masks for air and water vapour permeability testing, thermal conductivity, and a wear trial. It was found that masks with thin layers of woven fabric with low density were more having high breathability. Moreover, masks that contain adequate thermal conductivity and good water vapour permeability are a lot more easy to wear since these masks transfer heat and moisture from the body rapidly [62]. Furthermore, the mask should also maintain the temperature at a comfortable level. This depends on the application environment i.e. whether the mask is used inside buildings, or the mask is for outside environment which could be hot or cold conditions. In this context, Yang et al. (2017) electrospun nylon-6/needle-punched polyethylene filters were capable of filtering 99.6\% PM2.5 and further demonstrated a silver coating on the filters kept thermal comfort for the wearer depending on summer/winter season [63].

\subsubsection{Transparent masks}

H. Alenezi et al. (2020) designed a novel transparent filter mask with removable filters having minimal material requirement and unique air flow by using CFD studies thus increasing the likelihood trapping of contaminant particles. They observed via simulations that a turbulent flow within square waveform shaped filter design which through centrifugal forces traps air within the filter causing contaminant particles to hit the filter surface and increase filtration efficiency [64]. A non-filtering transparent face mask such as ClearMask ${ }^{\mathrm{TM}}$ developed by ClearMask LLC (https://www.theclearmask.com/), a Baltimore-based company in the USA, for differently abled persons with hearing disability, learning disability, autism, and/or dementia allowed clear full face visibility with lip reading to be done. The masks passed fluid resistance and flammability test. Since there is no airflow through the plastic sheet therefore, PFE, BFE, and pressure drop tests are not relevant to the ClearMask.

\subsubsection{Reusable masks}

S. Ullah et al. compared reusability of melt blown polypropylene vs. electrospun polyvinylidene fluoride (PVDF) nanofibers mask membranes by two different methods of disinfection (spraying or dipping) using $75 \%$ ethanol. They found that nanofiber filter materials retained filtration efficiency regardless of the disinfection method whereas melt blown material showed reduction in its filtration efficiency. On the other hand, air permeability decreased and pressure drop increased for nanofiber-based mask [65]. Recently, S. Park et al. (2021) fabricated sponge/cotton Janus filters with high filtration efficiency (99.99\%) and low pressure drops (61 Pa) with reusability up to 30 times [66]. S. S. Ray et al. (2020) demonstrated modification a commercial polyurethane masks via dip coating in a sonic bath of silica sol and alkylsilanol solution successively with a drying step, and curing at $100{ }^{\circ} \mathrm{C}$. The contact angle studies showed that coatings reduced sliding angle from $35^{\circ}$ (uncoated mask) to $17^{\circ}$, and a stable high contact angle of $132^{\circ}$ for $15 \mathrm{~min}$. They found that the coating had negligible effect on morphology of pores. Furthermore, coatings were stable without leak of silica particles and sustained water jet impacts up to $15 \mathrm{~min}$ in DI water [67].

T. Phan and C. Ching suggested conversion of a cardiopulmonary resuscitation (CPR) mask into a filtering mask by the use of cutting a non-woven face mask to the required dimensions and attach with a CPR mask which is easy to clean and reuse. After use, the piece of non-woven material can be thrown out and the CPR mask can be easily disinfected. They found that by this way a single face mask can be cut approximately into 6 pieces and used for at least 6 times safely instead of using a whole mask several times [68]. G.R. Swennen demonstrated fabrication of a 3-D-printed polyamide prototype face mask with good fit similar to the FFP2/3 masks. The prototype allowed use of a replaceable non-woven filter medium secured with a screw mechanism built into the mask. While the non-woven filter could be thrown away after use, the mask could be disinfected and reused after following the disinfection protocol [69].

Thus, the above research works indicate rapid prototyping can reduce time, minimize usage of precious N95 mask materials, and optimize the designs for high efficient cost effective filtration solution. Furthermore, highly reusable and rechargeable face masks can be developed with better comfort for the HCWs as well as the public.

\subsection{Material trends}

Nanomaterials are gaining importance in performance filtration materials for application in face masks. The recent research works have been summarized in Table 6 .

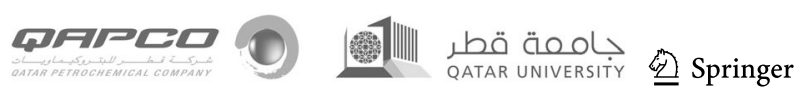




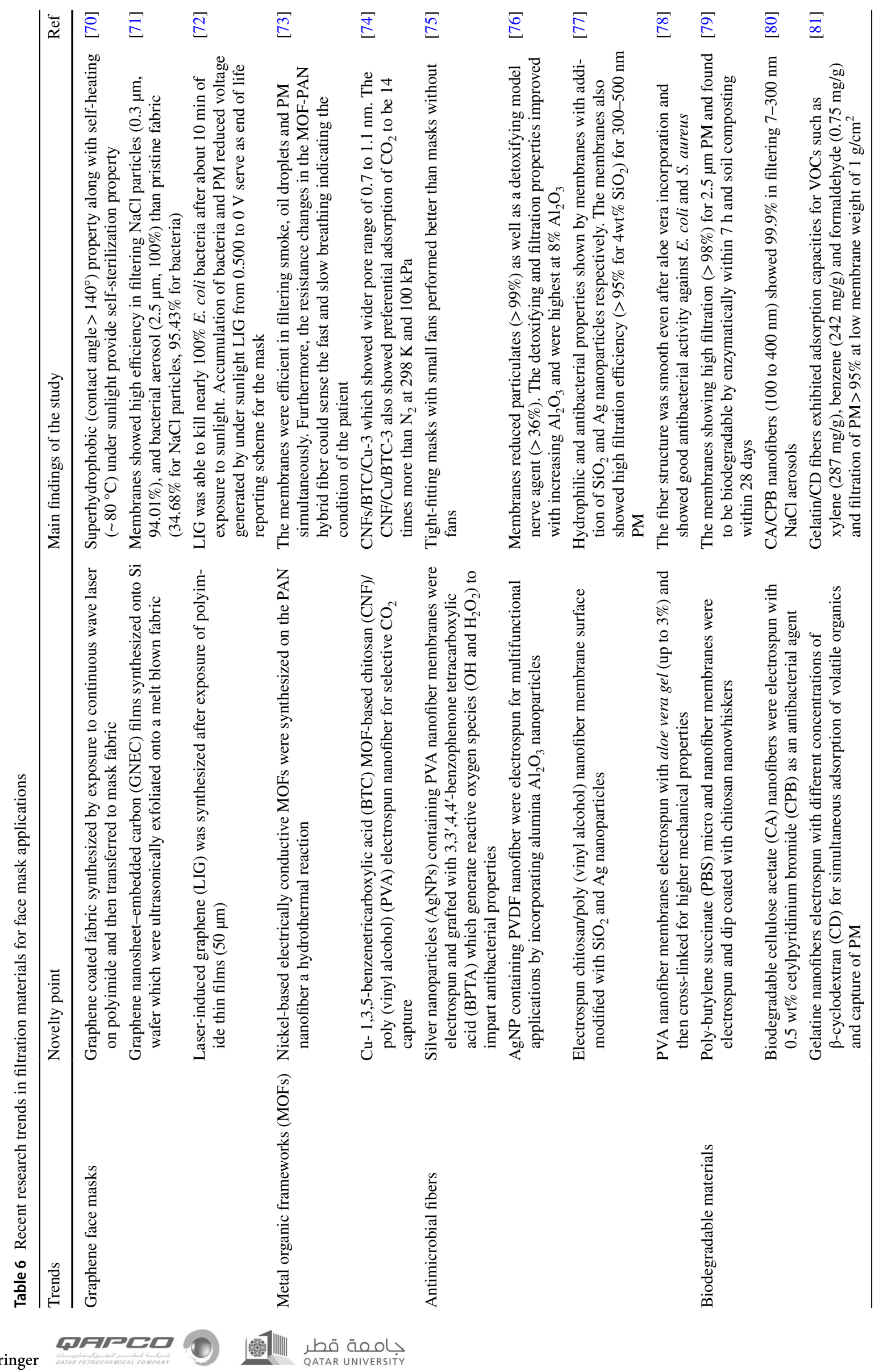




\subsubsection{Graphene face masks}

Use of graphene into a face mask can render super-hydrophobicity, self-sterilization [70, 71, 82], and sensing properties [72, 83]. For example, H. Zhong et al. synthesized graphene-coated fabric by exposure to continuous wave laser on polyimide and then transferring it to mask fabric. The fabric showed super hydrophobicity and self-sterilization via heating under sunlight exposure [70]. Z. Lin et al. used electron cyclotron resonance sputtering to grow graphene nanosheet-embedded carbon (GNEC) films onto Si wafer which is then exfoliated using an ultrasonic extrusion process onto a melt blown fabric. The GNEC fabric showed higher efficiency in filtering $\mathrm{NaCl}$ particles $(0.3 \mu \mathrm{m}$, $94.01 \%)$, and bacterial aerosol $(2.5 \mu \mathrm{m}, 100 \%)$ than pristine fabric (34.68\% for $\mathrm{NaCl}$ particles, $95.43 \%$ for bacteria) [71]. L. Huang et al. (2020) reported use of light-induced graphene (LIG) synthesized by laser exposure of polyimide with high antibacterial activities The LIG was able to kill nearly $100 \%$ E. coli bacteria after about $10 \mathrm{~min}$ of exposure to sunlight while activated carbon and melt blown fabrics killed $65 \%$ and $85 \%$ of the bacteria. The accumulation of bacteria $\left(6 \times 10^{4} \mathrm{cfu} / \mathrm{mm}^{2}\right)$ and PM $\left(1.5 \times 10^{-5} \mathrm{~g} / \mathrm{mm}^{2}\right)$ reduced the hygroscopic voltage from 0.500 to $0 \mathrm{~V}$ generated by the LIG which could serve as end of life reporting scheme for the mask [72].

\subsubsection{Metal organic framework (MOF) incorporated nanofibers}

MOFs have been incorporated into electrospun nanofibers and used for filtration/adsorption applications [84]. Recently, MOFs have been extended to provide sensing mechanisms in filter masks. For example, H. Lee et al. (2020) synthesized nickel-based electrically conductive MOF directly on the PAN nanofiber by hydrothermal reactions. The hybrid membranes were efficient in filtering smoke, oil droplets, and PM simultaneously. Furthermore, the resistance changes in the MOF-PAN hybrid fiber could sense the fast and slow breathing indicating the condition of the patient [73]. P. Jiamjirangkul fabricated Cu-BTC MOF-based chitosan (CNF)/poly (vinyl alcohol) (PVA) electrospun nanofiber for selective $\mathrm{CO}_{2}$ capture. They investigated different methods of preparation, and found that deposition of MOF after electrospinning fibers worked well as compared to in situ formation of MOF and mixing MOF into solution before the electrospinning. They also found the order of deposition of MOF influenced pore size and $\mathrm{CNFs} / \mathrm{Cu} / \mathrm{BTC}$ with 3 times BTC deposition showed more uniform pore range (0.6 to $0.8 \mathrm{~nm}$ ) as compared to $\mathrm{CNFs} / \mathrm{BTC} / \mathrm{Cu}-3$ which showed wider pore range of 0.7 to $1.1 \mathrm{~nm}$. The $\mathrm{CNF} / \mathrm{Cu} / \mathrm{BTC}-3$ also showed preferential adsorption of $\mathrm{CO}_{2}$ to be 14 times more than $\mathrm{N}_{2}$ at $298 \mathrm{~K}$ and $100 \mathrm{kPa}$ [74].

\subsubsection{Antimicrobial material}

Antibacterial face masks are gaining significance due to their enhanced ability to kill the microorganisms [85]. Silver nanoparticles are well known for their antimicrobial properties. S. Li et al. electrospun PVA nanofiber membranes containing Ag nanoparticles (AgNPs) and grafted with 3,3',4,4'-benzophenone tetracarboxylic acid (BPTA) which generate reactive oxygen species $\left(\mathrm{OH}\right.$ and $\left.\mathrm{H}_{2} \mathrm{O}_{2}\right)$ to impart antibacterial properties that was tested for reuse for about 7 times. The membranes showed good mechanical and filtration properties ( $>98 \%$, for $300-500 \mathrm{~nm} \mathrm{NaCl}$ particles) [75]. A. Vanagamudi et al. fabricated antibacterial AgNP-incorporated PVDF nanofibers capable of reducing particulates ( $>99 \%)$ as well as a detoxifying model nerve agent $(>36 \%)$. The detoxifying and filtration properties improved with increasing $\mathrm{Al}_{2} \mathrm{O}_{3}$ and were highest at $8 \%$ $\mathrm{Al}_{2} \mathrm{O}_{3}$ [76]. M. Zhu et al. electrospun chitosan/poly (vinyl alcohol) nanofiber membrane-modified surfaces with $\mathrm{SiO}_{2}$ and Ag nanoparticles to impart hydrophilic and antibacterial properties respectively. The membranes also showed high filtration efficiency ( $>95 \%$ for $4 \mathrm{wt} \% \mathrm{SiO}_{2}$ ) for $300-500 \mathrm{~nm}$ particles [77].

Bio-based antimicrobial additives are also gaining attraction due to their non-toxicity. H Khanzada et al. fabricated aloe vera gel (up to $3 \%$ ) incorporated into electrospun crosslinked PVA nanofibers. The fiber structure was smooth even after aloe vera incorporation and showed good antibacterial activity against $E$. coli and $S$. aureus [78]. Meanwhile, M.A Chowdhury et al. electrospun PVA solution containing licorice root extracts. Licorice root contains glycyrrhetinic acid (GA) and glycyrrhizin (GL) which are antimicrobial in nature. The fibers were in the range of $15-30 \mu \mathrm{m}$ and contained 0.021 licorice root particles $/ \mathrm{mm}^{2}$ [86].

S. Fauscher et al. (2020) conceptualized for the first time a mask with copper heating element to inactivate the virus. Through simulation studies, they found that with a copper heating mesh ( $0.6 \mathrm{~mm}$ wire diameter) incorporated into a mask of $0.3 \mathrm{~L}$ volume can achieve $\log 3$ to $\log 6$ reduction at $90{ }^{\circ} \mathrm{C}$ depending upon viral load in atmosphere [87].

\subsubsection{Biodegradable mask materials}

Plastics such as polyethylene and polypropylene do not degrade easily. Masks made with these materials might end up in landfills or polluting oceans, affecting aquatic life and finally enter human food chain $[88,89]$. Therefore, masks are expected to be made by biodegradable materials soon. Many environmentally friendly materials such as chitin, chitosan, cellulose, alginate, gelatine, silk fibroin, and keratin have been explored [54]. Recently, S. Choi et al. (2021) fabricated eco-friendly filter materials using poly-butylene succinate (PBS) electrospun micro and nanofiber membranes

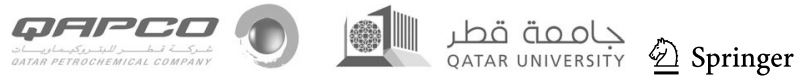


dip coated with chitosan nanowhiskers. The membranes showed high filtration ( $>98 \%$ ) for $2.5 \mu \mathrm{m}$ PM and were found to be biodegradable by enzymatically within $7 \mathrm{~h}$ and soil composting within 28 days [79].

Almeida et al. (2020) electrospun biodegradable cellulose acetate nanofibers with $0.5 \mathrm{wt} \%$ cetylpyridinium bromide (CPB) as an antibacterial agent. CA/CPB nanofibers (100 to $400 \mathrm{~nm}$ ) showed $99.9 \%$ in filtering $7-300 \mathrm{~nm} \mathrm{NaCl}$ aerosols [80]. V. Kadam et al. (2020) electrospun gelatin nanofibers with different concentrations of $\beta$-cyclodextran (CD) for simultaneous adsorption of volatile organics and capture of PM. The nanofibers shown adsorption capacities for xylene $(287 \mathrm{mg} / \mathrm{g})$, benzene $(242 \mathrm{mg} / \mathrm{g})$, and formaldehyde $(0.75 \mathrm{mg} / \mathrm{g})$ and filtration of $\mathrm{PM}>95 \%$ at low membrane weight of $1 \mathrm{~g} / \mathrm{cm}^{2}$ [81]. S. Ma et al. (2020) developed a biodegradable cellulose nanofiber-based multi-layer air filter consisting of Ag-MOFs@CNF@ZIF-8 with simultaneous reduction of PM2.5 (94.3\%), and gas $\mathrm{N}_{2}$ adsorption (109 $\mathrm{cm}^{3} / \mathrm{g}$ ). The membrane also displayed antibacterial properties with a zone inhibition diameter $\sim 18.1 \mathrm{~mm}$ and good compression strength of $501 \mathrm{kPa}$ [90].

A French company (https://www.geochanvre.fr/) is making face masks from hemp felts weighing $\sim 400 \mathrm{~g} / \mathrm{m}^{2}$ at about $2 \mathrm{~mL}$ thick. Although these masks seem heavy (two to four times the non-woven PP/PE textile masks), they are cheap and completely degradable since they are produced by using agro/natural resources. The mask is $98 \%$ efficient in filtering $3 \mu \mathrm{m}$ particulates [91].

Overall, the above literature indicates that electrospun nanofibers have gained commercial importance and the use of advanced materials such as graphene, $\mathrm{MOF}, \mathrm{SiO}_{2}$, and Ag nanoparticles is expected to impart multi-functionality to the filter membranes. Furthermore, the use of antimicrobial and biodegradable materials could be used to reduce the spread of disease and reduce environmental damages during pandemics.

\subsection{Important points to be noted in reporting future research}

The following points are to be noted while reporting the findings of the future research.

1. Most studies reported the pressure drops in units of 'Pascal (Pa)'. However, for industrial face mask applications, the pressure drops/differential pressure are reported in $\mathrm{Pa} / \mathrm{cm}^{2}$. Therefore, it will be helpful if researchers report the pressure drop in $\mathrm{Pa} / \mathrm{cm}^{2}$.

2. The nanofiber membranes are generally reported in terms of their thickness which could be erroneous as it is difficult to measure accurately due to the porous nature of such membranes. Inclusion of information such as weight per unit area $\left(\mathrm{g} / \mathrm{m}^{2}\right.$ or GSM) would be helpful for the textile community as a whole.

\subsection{Limitations of the present review}

Although this work is a comprehensive review on the latest trends and developments in the face mask manufacturing, the following are some of the limitations of this work:

1. This research highlighted the recent trends in materials and mechanical design aspects of face mask materials only. There could be other trends on each and every element of face masks such as sealing/joining processes, earloop materials, valve materials and designs, and recycling or disposal of face mask materials which are not the focus of this review.

2. This research highlighted the use of the electrospinning process and associated principles for face mask fabrication; however, other processes which are used for nonwoven material generation such as melt blowing and spun bonding were not covered in this review.

3. Attempts have been made to cover most recently published literatures during the SARS-CoV-2 pandemic; however, there could be more literature which might not have been covered in this manuscript.

4. Drawbacks of the new materials such as graphene/MoFs on human health and environment are yet to be known, so caution is to be followed while using these materials.

\section{Future prospects}

In future, face masks are expected to be manufactured with increasing complexity, for example inclusion of multiple micro-/nano-sensors embedded into the masks to support:

(i) Health monitoring by providing valuable health information of the wearer such as breathing levels, temperature, etc.;

(ii) Detection of environmental degradation by gas leaks/ pollution hazard/pathogen levels improving safety and well-being of the humans;

(iii) Face masks in future are expected to evolve from mere textile to high tech wearable electronics by further incorporation of software and IoT enabling automatically signalling of breathing associated stress to the family members or doctors. This paves the way for face masks to become a true multi-functional device;

(iv) The design of nearly complete transparent filtering masks supporting clear face to face communication for differently abled persons (hearing problem, learning disability, and dementia) simultaneously, allowing for 
the detection and filtration/neutralization of pathogens or chemical hazards;

(v) Long-term evaluation and certification of the recently developed face masks as deemed appropriate. Goodness of fit testing, moisture, and thermal management studies either by human subjects or manikin (dummies) studies can be taken up for these newly developing face masks.

\section{Concluding remarks}

The COVID-19 pandemic has catalysed the research and development of face masks. This review article attempted to cover rapid developments in research and development of face masks. The review article introduced general aspects of nanofiber face masks and performance parameters along with testing standards. Then, recent literatures were analysed and found developments in two aspects of face mask research i.e. materials used for face masks and rapid prototype designs of face masks. It was found that (i) electrospinning technology has been scaled up for commercial production of nanofiber face masks; (ii) novel organic and inorganic materials (biodegradable/antiviral nature, graphene, MoFs) introduced along with uses of nanofibers prepared by electrospinning process; and (iii) novel designs introduced by using the latest manufacturing and simulation technology such as 3-D printing which could optimize design for various requirements such as material cost, manufacturing time, weight, and wearer comfort for the new generation of face masks. Moreover, some future prospects were also identified for further development of face masks. The nanofiberbased face masks are promising new products with their high filtration efficiency and recent developments in materials and designs as discussed in this review. This review article will be helpful for the research community and industries involved in the design and manufacture of face masks.

Acknowledgements Mr. Veereshgouda S.N thanks CSIR, New Delhi for awarding SRF fellowship (31/003(0052)/2019-EMR-I) for pursuing his $\mathrm{PhD}$ work.

\section{Declarations}

Conflict of interest The authors declare no competing interests.

\section{References}

1. S.E. Eikenberry, M. Mancuso, E. Iboi, T. Phan, K. Eikenberry, Y. Kuang, E. Kostelich, A.B. Gumel, To mask or not to mask: modeling the potential for face mask use by the general public to curtail the COVID-19 pandemic. Infect. Dis. Model. 5, 293-308 (2020). https://doi.org/10.1016/j.idm.2020.04.001
2. M.H. Chua, W. Cheng, S.S. Goh, J. Kong, B. Li, J.Y.C. Lim, L. Mao, S. Wang, K. Xue, L. Yang, E. Ye, K. Zhang, W.C.D. Cheong, B.H. Tan, Z. Li, B.H. Tan, X.J. Loh, Face masks in the new COVID-19 normal: materials, testing, and perspectives. Research 2020, 7286735 (2020). https://doi.org/10.34133/2020/ 7286735

3. E.L. Anderson, P. Turnham, J.R. Griffin, C.C. Clarke, Consideration of the aerosol transmission for COVID-19 and public health. Risk Anal. 40, 902-907 (2020). https://doi.org/10.1111/risa.13500

4. L. Morawska, D.K. Milton, It is time to address airborne transmission of coronavirus disease 2019 (COVID-19). Clin. Infect. Dis. 71, 2311-2313 (2020). https://doi.org/10.1093/cid/ciaa939

5. M. Liao, H. Liu, X. Wang, X. Hu, Y. Huang, X. Liu, K. Brenan, J. Mecha, M. Nirmalan, J.R. Lu, A technical review of face mask wearing in preventing respiratory COVID-19 transmission. Curr. Opin. Colloid Interface Sci. 52, 101417 (2021). https://doi.org/10. 1016/j.cocis.2021.101417

6. H. Ueki, Y. Furusawa, K. Iwatsuki-Horimoto, M. Imai, H. Kabata, H. Nishimura, Y. Kawaoka, Effectiveness of face masks in preventing airborne transmission of SARS-CoV-2. MSphere 5, 2-6 (2020). https://doi.org/10.1128/msphere.00637-20

7. A. Agrawal, R. Bhardwaj, Reducing chances of COVID-19 infection by a cough cloud in a closed space. Phys. Fluids 32, 101704 (2020). https://doi.org/10.1063/5.0029186

8. A. Konda, A. Prakash, G.A. Moss, M. Schmoldt, G.D. Grant, S. Guha, Aerosol Filtration efficiency of common fabrics used in respiratory cloth masks. ACS Nano 14, 6339-6347 (2020). https:// doi.org/10.1021/acsnano.0c03252

9. F. Drewnick, J. Pikmann, F. Fachinger, L. Moormann, F. Sprang, S. Borrmann, Aerosol filtration efficiency of household materials for homemade face masks: influence of material properties, particle size, particle electrical charge, face velocity, and leaks. Aerosol Sci. Technol. 55, 63-79 (2021). https://doi.org/10.1080/ 02786826.2020 .1817846

10. P.W. Clapp, E.E. Sickbert-Bennett, J.M. Samet, J. Berntsen, K.L. Zeman, D.J. Anderson, D.J. Weber, W.D. Bennett, Evaluation of cloth masks and modified procedure masks as personal protective equipment for the public during the COVID-19 pandemic. JAMA Intern. Med. 27599, 1-7 (2020). https://doi.org/10.1001/ jamainternmed.2020.8168

11. A.N. Desai, P. Mehrotra, Medical masks. JAMA 323, 1517-1518 (2020). https://doi.org/10.1001/jama.2020.2331

12. M. Karmacharya, S. Kumar, O. Gulenko, Y.-K. Cho, Advances in facemasks during the COVID-19 pandemic era. ACS Appl. Bio Mater. 4, 3891-3908 (2021). https://doi.org/10.1021/acsabm. 0c01329

13. K.P. Singh, D. Mohan, G.S. Tandon, G.S.D. Gupta, Vapor-phase adsorption of hexane and benzene on activated carbon fabric cloth: equilibria and rate studies $\dagger$. Ind. Eng. Chem. Res. 41, 2480-2486 (2002). https://doi.org/10.1021/ie0105674

14 J.G. McCulloch, The history of the development of melt blowing technology. Int. Nonwovens J. os-8, 1558925099os-80 (1999). https://doi.org/10.1177/1558925099OS-800123

15. P.K. Panda, B. Sahoo, Synthesis and Applications of Electrospun Nanofibers, in: N. Navaan, S. Sinha, J. Govil (Eds.), Nanotechnol. Vol 1 Fundam. Appl., 1st ed., Studium Press LLC, USA, Houston, Texas, 2013: pp. 399-416. https://www.researchgate. net/publication/259824059.

16. Z. Zhang, D. Ji, H. He, S. Ramakrishna, Electrospun ultrafine fibers for advanced face masks. Mater. Sci. Eng. R Reports 143, 100594 (2021). https://doi.org/10.1016/j.mser.2020.100594

17. A. Formhals, Process and apparatus for preparing artificial threads, 1,975,504, 1934.

18. S. Ramakrishna, K. Fujihara, W.E. Teo, T.C. Lim, Z. Ma, An introduction to electrospinning and nanofibers. World Scientific (2005). https://doi.org/10.1142/5894 
19. J. Doshi, D.H. Reneker, Electrospinning process and applications of electrospun fibers, in: Conf. Rec. 1993 IEEE Ind. Appl. Conf. Twenty-Eighth IAS Annu. Meet., IEEE, 1993: pp. 1698-1703. https://doi.org/10.1109/IAS.1993.299067.

20. L. Persano, A. Camposeo, C. Tekmen, D. Pisignano, Industrial upscaling of electrospinning and applications of polymer nanofibers: a review. Macromol. Mater. Eng. 298, 504-520 (2013). https://doi.org/10.1002/mame.201200290

21. U. Ali, Y. Zhou, X. Wang, T. Lin, Direct electrospinning of highly twisted, continuous nanofiber yarns. J. Text. Inst. 103, 80-88 (2012). https://doi.org/10.1080/00405000.2011.552254

22. R.S. Barhate, S. Ramakrishna, Nanofibrous filtering media: filtration problems and solutions from tiny materials. J. Memb. Sci. 296, 1-8 (2007). https://doi.org/10.1016/j.memsci.2007.03. 038

23. V.S. Naragund, P.K. Panda, Electrospun polyacrylonitrile nanofiber membranes for air filtration application. Int. J. Environ. Sci. Technol. (2021). https://doi.org/10.1007/s13762-021-03705-4

24. M. Cheng, Z. Qin, S. Hu, H. Yu, M. Zhu, Use of electrospinning to directly fabricate three-dimensional nanofiber stacks of cellulose acetate under high relative humidity condition. Cellulose 24, 219-229 (2017). https://doi.org/10.1007/s10570-016-1099-3

25. V.S. Naragund, P.K. Panda, Electrospinning of polyacrylonitrile nanofiber membrane for bacteria removal. J. Mater. Sci. Appl. 4, 68-74 (2018). https://doi.org/10.5281/zenodo.3344559

26. B. Sahoo, P.K. Panda, Synthesis and characterization of manganese tetroxide (Mn3O4) nanofibers by electrospinning technique. J. Adv. Ceram. 2, 26-30 (2013). https://doi.org/10.1007/ s40145-013-0037-1

27. M. Chandraiah, B. Sahoo, P.K. Panda, Preparation and characterization of $\mathrm{SnO} 2$ nanofibers by electrospinning. Trans. Indian Ceram. Soc. 73, 266-269 (2014). https://doi.org/10.1080/03717 50X.2014.923786

28. V.S. Naragund, P.K. Panda, Electrospinning of cellulose acetate nanofiber membrane using methyl ethyl ketone and N, N-dimethylacetamide as solvents. Mater. Chem. Phys. 240, 122147 (2020). https://doi.org/10.1016/j.matchemphys.2019.122147

29. T. Grafe, K. Graham, Nanofiber Webs from Electrospinning, in: Nonwovens Filtr. Int. Conf., 2003: pp. 1-5.

30. R. Wang, S. Guan, A. Sato, X. Wang, Z. Wang, R. Yang, B.S. Hsiao, B. Chu, Nanofibrous microfiltration membranes capable of removing bacteria, viruses and heavy metal ions. J. Memb. Sci. 446, 376-382 (2013). https://doi.org/10.1016/j.memsci.2013.06. 020

31. X. Zhao, S. Wang, X. Yin, J. Yu, B. Ding, Slip-effect functional air filter for efficient purification of PM 2.5. Sci. Rep. 6, 1-11 (2016). https://doi.org/10.1038/srep35472

32. A. Raksa, P. Numpaisal, Y. Ruksakulpiwat, The effect of humidity during electrospinning on morphology and mechanical properties of SF/PVA nanofibers. Mater. Today Proc. 10-13 (2021). https:// doi.org/10.1016/j.matpr.2021.03.459.

33. C.L. Casper, J.S. Stephens, N.G. Tassi, D.B. Chase, J.F. Rabolt, Controlling surface morphology of electrospun polystyrene fibers: effect of humidity and molecular weight in the electrospinning process. Macromolecules 37, 573-578 (2004). https://doi.org/10. 1021/ma0351975

34. P.K. Szewczyk, D.P. Ura, U. Stachewicz, Humidity controlled mechanical properties of electrospun polyvinylidene fluoride (Pvdf) fibers. Fibers 8, 1-9 (2020). https://doi.org/10.3390/fib81 00065

35. A. Koski, K. Yim, S. Shivkumar, Effect of molecular weight on fibrous PVA produced by electrospinning. Mater. Lett. 58, 493 497 (2004). https://doi.org/10.1016/S0167-577X(03)00532-9

36. T. Uyar, F. Besenbacher, Electrospinning of uniform polystyrene fibers: the effect of solvent conductivity. Polymer (Guildf). 49, 5336-5343 (2008). https://doi.org/10.1016/j.polymer.2008.09.025
37. T. Lin, H. Wang, H. Wang, X. Wang, The charge effect of cationic surfactants on the elimination of fibre beads in the electrospinning of polystyrene. Nanotechnology 15, 1375-1381 (2004). https:// doi.org/10.1088/0957-4484/15/9/044

38. W. Liu, C. Huang, X. Jin, Electrospinning of grooved polystyrene fibers: effect of solvent systems. Nanoscale Res. Lett. 10, 237 (2015). https://doi.org/10.1186/s11671-015-0949-5

39. J.Y. Park, I.H. Lee, G.N. Bea, Optimization of the electrospinning conditions for preparation of nanofibers from polyvinylacetate (PVAc) in ethanol solvent. J. Ind. Eng. Chem. 14, 707-713 (2008). https://doi.org/10.1016/j.jiec.2008.03.006

40 R.R. Bresee, W.-C. Ko, Fiber formation during melt blowing. Int. Nonwovens J. os-12, 1558925003os-12 (2003). https://doi.org/10. 1177/1558925003os-1200209

41. D. Das, R. Thakur, A.K. Pradhan, Optimization of corona discharge process using Box-Behnken design of experiments. J. Electrostat. 70, 469-473 (2012). https://doi.org/10.1016/j.elstat.2012. 07.005

42 T. Grafe, K. Graham, Polymeric nanofibers and nanofiber webs: a new class of nonwovens. Int. Nonwovens J. os-12, 1558925003os12 (2003). https://doi.org/10.1177/1558925003os-1200113

43. Z. Ma, M. Kotaki, S. Ramakrishna, Electrospun cellulose nanofiber as affinity membrane. J. Memb. Sci. 265, 115-123 (2005). https://doi.org/10.1016/j.memsci.2005.04.044

44. R.L. Shambaugh, A macroscopic view of the melt-blowing process for producing microfibers. Ind. Eng. Chem. Res. 27, 23632372 (1988). https://doi.org/10.1021/ie00084a021

45. C.J. Ellison, A. Phatak, D.W. Giles, C.W. Macosko, F.S. Bates, Melt blown nanofibers: fiber diameter distributions and onset of fiber breakup. Polymer (Guildf). 48, 3306-3316 (2007). https:// doi.org/10.1016/j.polymer.2007.04.005

46. S.S. Ray, S.S. Chen, C.W. Li, N.C. Nguyen, H.T. Nguyen, A comprehensive review: electrospinning technique for fabrication and surface modification of membranes for water treatment application. RSC Adv. (2016). https://doi.org/10.1039/c6ra14952a

47. P.K. Panda, B. Sahoo, Water purification by removal of pathogens using electrospun polymer nanofiber membranes: a review. J. Mater. Sci. Appl. 5, 1-8 (2019) http://www.aascit.org/journal/ archive 2 .journalId $=891$ \& paperId $=7221$

48. W.W.F. Leung, Q. Sun, Electrostatic charged nanofiber filter for filtering airborne novel coronavirus (COVID-19) and nano-aerosols. Sep. Purif. Technol. 250, 116886 (2020). https://doi.org/10. 1016/j.seppur.2020.116886

49. R.L. Smith, R. Pieters, M.E. Morrison, Fundamentals of falsetwist texturing of thermoplastic continuous filament yarns. Trans. Soc. Rheol. 16, 557-576 (1972). https://doi.org/10.1122/1.549264

50. ASTM F2100-20, Standard Specification for Performance of Materials Used in Medical Face Masks, in: F23.40 (Ed.), Occup. Heal. Safety; Prot. Cloth., 2020th ed., ASTM International, West Conshohocken, PA, 2020: p. 4. https://doi.org/10.1520/F2100-20.

51. S. Rengasamy, R. Shaffer, B. Williams, S. Smit, A comparison of facemask and respirator filtration test methods. J. Occup. Environ. Hyg. 14, 92-103 (2017). https://doi.org/10.1080/15459624.2016. 1225157

52. BS EN149:2001+A1, BS EN149: 2001 + A1 2009. Respiratory protective devices. Filtering half masks to protect against particles. Requirements, testing, marking, 2009.

53. V.R. Gaitan, L. Alejandra, COVID-19 technical specifications for personal protective equipment and related IPC supplies. World Heal. Organ. 57 (2020). https://www.who.int/medical_devices/ priority/Technical_Specs_PPE_Covid19_final_V6.docx?ua=1. Accessed February 27, 2020.

54. V. Shanmugam, K. Babu, T.F. Garrison, A.J. Capezza, R.T. Olsson, S. Ramakrishna, M.S. Hedenqvist, S. Singha, M. Bartoli, M. Giorcelli, G. Sas, M. Försth, O. Das, Á. Restás, F. Berto, Potential natural polymer-based nanofibres for the development 
of facemasks in countering viral outbreaks. J. Appl. Polym. Sci. 138(27), 50658 (2021). https://doi.org/10.1002/app.50658

55. CEN/TC 205/WG 14, EN 14683:2019+AC:2019 (E) Medical face masks - requirements and test methods, Brussels, 2019.

56. J. Yuk, B. Anuj, C. Benjamin, F. Karl, M. Daniel, C. Chun-I, J. Ashley, B. Saikat, C. Leonardo, J. Sunghwan, 3D-printing Mask filters inspired by animal nasal cavity, in: Bull. Am. Phys. Soc., American Physical Society, Chicago, 2020.

57. H. Liu, L. Liu, J. Yu, X. Yin, B. Ding, High-efficiency and super-breathable air filters based on biomimetic ultrathin nanofiber networks. Compos. Commun. 22, 100493 (2020). https://doi.org/10.1016/j.coco.2020.100493

58. P. Piombino, U. Committeri, G. Norino, L.A. Vaira, S. Troise, F. Maglitto, D. Mariniello, G. De Riu, L. Califano, Facing COVID-19 pandemic: development of custom-made face mask with rapid prototyping system. J. Infect. Dev. Ctries. 15, 51-57 (2021). https://doi.org/10.3855/jidc. 13384

59. R. Zhang, Q. Xu, S. Bai, J. Hai, L. Cheng, G. Xu, Y. Qin, Enhancing the filtration efficiency and wearing time of disposable surgical masks using TENG technology. Nano Energy 79, 105434 (2021). https://doi.org/10.1016/j.nanoen.2020.105434

60. Y. Si, Z. Zhang, W. Wu, Q. Fu, K. Huang, N. Nitin, B. Ding, G. Sun, Daylight-driven rechargeable antibacterial and antiviral nanofibrous membranes for bioprotective applications. Sci. Adv. 4, eaar5931 (2018). https://doi.org/10.1126/sciadv.aar5931

61. S. Choi, R. Park, N. Hur, W. Kim, Evaluation of wearing comfort of dust masks. PLoS ONE 15, 1-13 (2020). https://doi.org/ 10.1371/journal.pone. 0237848

62. K.P. Lee, J. Yip, C.W. Kan, J.C. Chiou, K.F. Yung, Reusable face masks as alternative for disposable medical masks: factors that affect their wear-comfort. Int. J. Environ. Res. Public Health 17, 1-16 (2020). https://doi.org/10.3390/ijerph17186623

63. A. Yang, L. Cai, R. Zhang, J. Wang, P.-C. Hsu, H. Wang, G. Zhou, J. Xu, Y. Cui, Thermal management in nanofiber-based face mask. Nano Lett. 17, 3506-3510 (2017). https://doi.org/10. 1021/acs.nanolett.7b00579

64. H. Alenezi, M.E. Cam, M. Edirisinghe, A novel reusable antiCOVID-19 transparent face respirator with optimized airflow. Bio-Design Manuf. 4, 1-9 (2021). https://doi.org/10.1007/ s42242-020-00097-1

65. S. Ullah, A. Ullah, J. Lee, Y. Jeong, M. Hashmi, C. Zhu, K. Il Joo, H.J. Cha, I.S. Kim, Reusability comparison of melt-blown vs nanofiber face mask filters for use in the coronavirus pandemic. ACS Appl. Nano Mater. 3, 7231-7241 (2020). https:// doi.org/10.1021/acsanm.0c01562

66. S. Park, H.Y. Koo, C. Yu, W.S. Choi, A novel approach to designing air filters: ubiquitous material-based Janus air filter modules with hydrophilic and hydrophobic parts. Chem. Eng. J. 410, 128302 (2021). https://doi.org/10.1016/j.cej.2020.128302

67. S.S. Ray, Y.I. Park, H. Park, S.E. Nam, I.C. Kim, Y.N. Kwon, Surface innovation to enhance anti-droplet and hydrophobic behavior of breathable compressed-polyurethane masks. Environ. Technol. Innov. 20, 101093 (2020). https://doi.org/10. 1016/j.eti.2020.101093

68. T.L. Phan, C.T.-S. Ching, A reusable mask for coronavirus disease 2019 (COVID-19). Arch. Med. Res. 51, 455-457 (2020). https://doi.org/10.1016/j.arcmed.2020.04.001

69. G.R.J. Swennen, L. Pottel, P.E. Haers, Custom-made 3D-printed face masks in case of pandemic crisis situations with a lack of commercially available FFP2/3 masks. Int. J. Oral Maxillofac. Surg. 49, 673-677 (2020). https://doi.org/10.1016/j.ijom.2020. 03.015

70. H. Zhong, Z. Zhu, J. Lin, C.F. Cheung, V.L. Lu, F. Yan, C.-Y. Chan, G. Li, Reusable and recyclable graphene masks with outstanding superhydrophobic and photothermal performances.
ACS Nano 14, 6213-6221 (2020). https://doi.org/10.1021/acsna no. $0 \mathrm{c} 02250$

71. Z. Lin, Z. Wang, X. Zhang, D. Diao, Superhydrophobic, photosterilize, and reusable mask based on graphene nanosheet-embedded carbon (GNEC) film. Nano Res. 14, 1110-1115 (2021). https://doi.org/10.1007/s12274-020-3158-1

72. L. Huang, S. Xu, Z. Wang, K. Xue, J. Su, Y. Song, S. Chen, C. Zhu, B.Z. Tang, R. Ye, Self-reporting and photothermally enhanced rapid bacterial killing on a laser-induced graphene mask. ACS Nano 14, 12045-12053 (2020). https://doi.org/10. 1021/acsnano.0c05330

73. H. Lee, S. Jeon, Polyacrylonitrile nanofiber membranes modified with Ni-based conductive metal organic frameworks for air filtration and respiration monitoring. ACS Appl. Nano Mater. 3, 8192-8198 (2020). https://doi.org/10.1021/acsanm.0c01619

74. P. Jiamjirangkul, T. Inprasit, V. Intasanta, A. Pangon, Metal organic framework-integrated chitosan/poly(vinyl alcohol) (PVA) nanofibrous membrane hybrids from green process for selective CO2 capture and filtration. Chem. Eng. Sci. 221, 115650 (2020). https://doi.org/10.1016/j.ces.2020.115650

75. S. Li, R. Zhang, J. Xie, D.E. Sameen, S. Ahmed, J. Dai, W. Qin, S. Li, Y. Liu, Electrospun antibacterial poly(vinyl alcohol)/Ag nanoparticles membrane grafted with 3,3',4,4'-benzophenone tetracarboxylic acid for efficient air filtration. Appl. Surf. Sci. 533, 147516 (2020). https://doi.org/10.1016/j.apsusc.2020.147516

76. A. Vanangamudi, S. Hamzah, G. Singh, Synthesis of hybrid hydrophobic composite air filtration membranes for antibacterial activity and chemical detoxification with high particulate filtration efficiency (PFE). Chem. Eng. J. 260, 801-808 (2015). https://doi. org/10.1016/j.cej.2014.08.062

77. M. Zhu, R. Xiong, C. Huang, Bio-based and photocrosslinked electrospun antibacterial nanofibrous membranes for air filtration. Carbohydr. Polym. 205, 55-62 (2019). https://doi.org/10.1016/j. carbpol.2018.09.075

78. H. Khanzada, A. Salam, M.B. Qadir, D.N. Phan, T. Hassan, M.U. Munir, K. Pasha, N. Hassan, M.Q. Khan, I.S. Kim, Fabrication of promising antimicrobial aloe vera/PVA electrospun nanofibers for protective clothing. Materials (Basel). 13, 3884 (2020). https:// doi.org/10.3390/MA13173884

79. S. Choi, H. Jeon, M. Jang, H. Kim, G. Shin, J.M. Koo, M. Lee, H.K. Sung, Y. Eom, H.S. Yang, J. Jegal, J. Park, D.X. Oh, S.Y. Hwang, Biodegradable, efficient, and breathable multi-use face mask filter. Adv. Sci. 8, 2003155 (2021). https://doi.org/10.1002/ advs. 202003155

80. D.S. de Almeida, L.D. Martins, E.C. Muniz, A.P. Rudke, R. Squizzato, A. Beal, P.R. de Souza, D.P.F. Bonfim, M.L. Aguiar, M.L. Gimenes, Biodegradable CA/CPB electrospun nanofibers for efficient retention of airborne nanoparticles. Process Saf. Environ. Prot. 144, 177-185 (2020). https://doi.org/10.1016/j.psep.2020. 07.024

81. V. Kadam, Y.B. Truong, J. Schutz, I.L. Kyratzis, R. Padhye, L. Wang, Gelatin/ $\beta$-cyclodextrin bio-nanofibers as respiratory filter media for filtration of aerosols and volatile organic compounds at low air resistance. J. Hazard. Mater. 403, 123841 (2021). https:// doi.org/10.1016/j.jhazmat.2020.123841

82. K. Pal, G.Z. Kyzas, S. Kralj, F.G. de Souza, Sunlight sterilized, recyclable and super hydrophobic anti-COVID laser-induced graphene mask formulation for indelible usability. J. Mol. Struct. 1233, 130100 (2021). https://doi.org/10.1016/j.molstruc.2021. 130100

83. J. van den Broek, I.C. Weber, A.T. Güntner, S.E. Pratsinis, Highly selective gas sensing enabled by filters. Mater. Horizons (2021). https://doi.org/10.1039/D0MH01453B

84. D.K. Yoo, H.C. Woo, S.H. Jhung, Removal of particulate matter with metal-organic framework-incorporated materials. Coord.

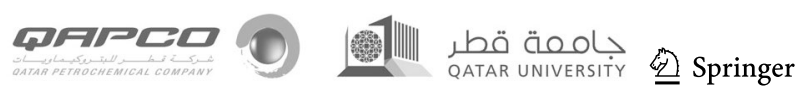


Chem. Rev. 422, 213477 (2020). https://doi.org/10.1016/j.ccr. 2020.213477

85. G. Pullangott, U. Kannan, S. Gayathri, D.V. Kiran, S.M. Maliyekkal, A comprehensive review on antimicrobial face masks: an emerging weapon in fighting pandemics. RSC Adv. 11, 65446576 (2021). https://doi.org/10.1039/D0RA10009A

86. M.A. Chowdhury, M.B.A. Shuvho, M.A. Shahid, A.K.M.M. Haque, M.A. Kashem, S.S. Lam, H.C. Ong, M.A. Uddin, M. Mofijur, Prospect of biobased antiviral face mask to limit the coronavirus outbreak. Environ. Res. 192, 110294 (2021). https:// doi.org/10.1016/j.envres.2020.110294

87. S. Faucher, D.J. Lundberg, X.A. Liang, X. Jin, R. Phillips, D. Parviz, J. Buongiorno, M.S. Strano, A virucidal face mask based on the reverse flow reactor concept for thermal inactivation of SARS-CoV-2. AIChE J. 67(6), e17250 (2021). https://doi.org/10. 1002/aic. 17250
88. O.O. Fadare, B. Wan, L.-H. Guo, L. Zhao, Microplastics from consumer plastic food containers: are we consuming it? Chemosphere 253, 126787 (2020). https://doi.org/10.1016/j.chemosphere. 2020.126787

89. O.O. Fadare, E.D. Okoffo, Covid-19 face masks: a potential source of microplastic fibers in the environment. Sci. Total Environ. 737, 140279 (2020). https://doi.org/10.1016/j.scitotenv.2020.140279

90 S. Ma, M. Zhang, J. Nie, J. Tan, B. Yang, S. Song, Design of double-component metal-organic framework air filters with PM2.5 capture, gas adsorption and antibacterial capacities. Carbohydr. Polym. 203, 415-422 (2019). https://doi.org/10.1016/j.carbpol. 2018.09.039

91. Geochanvre, Geochanvre Masque Biocompostable. 2 (2020). https://www.geochanvre.fr/wp-content/uploads/2020/10/200908_ MasqueBiocompostable_Geochanvre_Fiche_Produit_UNS1.pdf. accessed June 27, 2021. 